\title{
A constituição do movimento Campo de Públicas a partir da percepção de integrantes graduados em Administração
}

\section{The establishment of the Public Field movement from the perception of Management undergrads}

Sílvia Ferreira Caproni Gonçalves

Mestrado em Gestão Pública e Sociedade pelo Instituto de Ciências Sociais de Americana, Técnica em Assuntos Educacionais na Coordenadoria de Graduação da Unifal- Mg, Brasil

silvia.goncalves@unifal-mg.edu.br

http://lattes.cnpq.br/7306685850456001

Virgílio Cézar da Silva Oliveira

Doutorado em Administração pela Universidade Federal de Lavras, Professor da Universidade Federal de Juiz de Fora, Brasil

virgilio.oliveira@ufjf.edu.br

http://lattes.cnpq.br/0934800941246776

Resumo: O Campo de Públicas é um movimento multidisciplinar formado por discentes e docentes ligados aos cursos que formam gestores públicos e que, a partir de 2010, intensificou a discussão de assuntos relevantes à esfera pública. Esta pesquisa qualitativa busca compreender a constituição deste movimento a partir de referenciais teóricos sobre identidade fornecidos pela Psicologia Social e pela análise de entrevistas realizadas com integrantes graduados em Administração. Constatou-se, a partir das falas dos entrevistados que a negação da identidade pressuposta de administrador foi um fator determinante para o seu ingresso no referido movimento e que a natureza da identidade coletiva em construção expressa em suas entrevistas é de resistência à imposição de referenciais típicos da ciência administrativa hegemônica. Dinâmicas associadas ao movimento sinalizam em direção à uma identidade de projeto, ancorada na multiplicidade da formação de seus atores.

Palavras-chave: Administração Pública; Psicologia Social; identidade.

Abstract: The Public Field is a multidisciplinary movement formed by students and teachers linked to courses that graduate public managers. The Public Field movement has intensified the discussion of relevant issues to the public sphere since 2010. This qualitative research aims to understand the constitution of the movement from theoretical frameworks of identity provided by social psychology and by analysis of interviews that were conducted with senior members in management. It was found, from the speeches of the interviewees, that the denial of this identity was essential for their entrance in the movement. The nature of collective identity under construction expressed in the speeches of the respondents is a resistance to the imposition of typical reference of the hegemonic administrative science. Dynamics associated with the Public Field signal towards a project identity, anchored in the multiplicity of training of its actors.

Key-words: Brazilian Public Administration. Social Psychology. Identity.

Texto completo em português: http://www.apgs.ufv.br Full text in Portuguese: http://www.apgs.ufv.br

\section{Introdução}

Com o processo de redemocratização, o Brasil reconfigurou a natureza das relações entre sociedade e Estado, demandando transformações políticas, organizacionais e gerenciais. $\mathrm{Na}$ Constituição Federal de 1988 foram incluídos direitos políticos e sociais como saúde, educação, assistência social e amparo à infância e à adolescência. A necessidade de atendimento a tais direitos ampliou as demandas junto ao Estado brasileiro e, consequentemente, a exigência de eficiência por parte da Administração Pública e de seus técnicos. Em relação à educação, houve no Brasil das últimas décadas, uma expansão do sistema de ensino superior com um crescimento acentuado do número de cursos de graduação cadastrados no MEC - Ministério de Educação. De acordo com dados do censo de 2012, o número de cursos de graduação passou de 4.908 em 1991 para 23.488 em 2007 (Brasil, 2012a).

Os fatos acima colocam em relevo o debate sobre o perfil profissional necessário aos gestores públicos, egressos ou não desses novos cursos. Nesse sentido, Keinert (1994, 2000), Nogueira (1998) e Coelho $(2006,2011,2014)$ alertam para a especificidade da Administração Pública, que possui uma lógica distinta da administração de empresas. Enquanto a primeira orienta-se para a promoção do bem comum, devendo ser crítica à natureza de seus fins, a segunda orienta-se para a performance, dedicando-se essencialmente ao emprego de meios capazes de promovê-la. Para defender o argumento de que a Administração Pública tem uma lógica própria, Paes de Paula (2005) afirma que sua efetividade requer o desenvolvimento de técnicas de gestão adequadas, além de uma formação específica voltada para si mesma.

Alinhados a essa perspectiva, docentes da referida área organizaram um fórum permanente voltado à discussão de assuntos relevantes para os cursos centrados nas especificidades e nas demandas da esfera pública. Esse grupo, que intensificou suas atividades a partir do ano de 2010, ficou conhecido como movimento Campo de Públicasi que tem se revelado um ente ativo na redefinição de parâmetros e práticas de formação de gestores públicos. O posicionamento de rejeição de referenciais próprios da administração de empresas e o engajamento do Campo de Públicas foram determinantes para a aprovação, pelo Conselho Nacional de Educação, de Diretrizes Curriculares específicas para cursos de graduação em Administração Pública (Resolução n. 1,

Correspondência/Correspondence: Universidade Federal de Alfenas, Campus Varginha. Avenida Celina Ferreira Otoni, 4000. Padre Vitor. 37048395 Varginha, MG - Brasil

silvia.goncalves@unifal-mg.edu.br, 
2014). Até então, estes cursos de graduação estavam submetidos à Resolução n. 4 (2005), que estabelecia as Diretrizes Curriculares Nacionais - DCN - para os cursos de Bacharelado em Administração.

Para o desenvolvimento da pesquisa que embasou esse trabalho foram utilizadas algumas formas de contato com 0 movimento, tanto presencial quanto o acompanhamento através do fórum e, desde as primeiras interações com o grupo foi possível perceber a busca pela valorização da Administração Pública e o respeito às particularidades que envolvem a formação dos gestores públicos. Em busca de um direcionamento para a investigação, além dos estudos relacionados à formação dos gestores públicos, o campo da Psicologia Social foi acessado, para provisão de referenciais sobre identidades individuais e coletivas. Partindo das considerações anteriores, este trabalho busca compreender a constituição do Campo de Públicas a partir da percepção de integrantes graduados em Administração e do seu posicionamento diante da identidade pressuposta de administrador. Tendo esse foco, o estudo foi direcionado para:

a) discutir os referenciais fundamentais da ciência administrativa, isto é, os elementos que estabelecem a identidade pressuposta do administrador;

b) analisar o discurso de integrantes do Campo de Públicas, de modo a verificar seu posicionamento de assimilação, reposição ou negação em relação à identidade pressuposta do administrador;

c) discutir a natureza fundamental, de resistência ou de projeto, dessa identidade coletiva em formação.

Apesar do movimento Campo de Públicas contar com integrantes de diversas áreas de formação, a parte empírica da pesquisa foi desenvolvida através de entrevistas direcionadas aos graduados em Administração por terem sido considerados os mais aptos a expressarem um posicionamento diante da identidade pressuposta de administrador.

Ao discutir a constituição da identidade do movimento Campo de Públicas - identidade coletiva, portanto - a pesquisa encontrou em Castells (2010) uma discussão significativa que considera a importância das relações de poder nos processos de constituição de identidades coletivas. O autor propõe uma distinção entre três formas e origens das identidades: legitimadora, de resistência ou de projeto. Os conceitos em itálico citados serão pormenorizados no referencial teórico.

Ao tratar da constituição identitaria, o trabalho conta ainda com as contribuições de Ciampa (1987, 1994), que trata de identidade pressuposta e do posicionamento dos indivíduos diante das diferentes identidades que Ihes são apresentadas ao longo da vida. Segundo o autor, a identidade é socialmente construída a partir dos diferentes posicionamentos adotados, assimilando-as, repondo-as ou negando-as num processo constante, como uma metamorfose.

A partir dos dados coletados (entrevistas) empregou-se a Análise de Conteúdo segundo Bardin (2011). As categorias de análise foram elaboradas em dois momentos distintos: primeiramente, a partir do referencial teórico e, depois, outras categorias foram elaboradas após a realização das entrevistas.

Ainda sobre a seleção do Campo de Públicas como objeto de investigação, ela se sustenta pelas demonstrações de força política do movimento, impactando, inclusive, as decisões do Conselho Nacional de Educação. Cumpre destacar sua potencialidade de contribuir para o posicionamento da dimensão sociopolítica da Administração Pública no mesmo patamar de importância das dimensões institucional-administrativa e econômico-financeira e por defender a formação substantiva (e não apenas instrumental) do gestor público, fato que se desdobra em componentes éticos e políticos de seu perfil.

Este artigo está organizado em seis seções: esta primeira, a introdução; a segunda, que contextualiza a pesquisa e apresenta o Campo de Públicas; a terceira, que detalha o referencial teórico e aborda a constituição de identidades individuais e coletivas, além da identidade pressuposta do administrador; a quarta, que trata dos procedimentos metodológicos; a quinta, que analisa os resultados e sugere um dos condicionantes da origem do Campo de Públicas, e a sexta, que apresenta as considerações finais, buscando apresentar algumas contribuições para a reflexão sobre a constituição do movimento Campo de Públicas e indica uma agenda de pesquisas futuras.

\section{A trajetória dos cursos de Administração Pública no Brasil e o Campo de Públicas}

Em função do conjunto de direitos garantidos pela Constituição, do intenso debate sobre a necessidade de se reformar o Estado e, na década de 2000, da ampliação dos investimentos em educação superior, a formação de gestores públicos ganhou novo fôlego, despertando o interesse do governo e da sociedade. O lançamento, em 2009, do Programa Nacional de Formação em Administração Pública (PNAP) pode ser considerado um reflexo desse fato. É, portanto, nesse contexto que o movimento Campo de Públicas foi criado.

De acordo com Pires, Vainer e Fonseca (2012), o Campo de Públicas é um espaço multidisciplinar de formação acadêmica, científica e profissional, comprometido com o aperfeiçoamento democrático e republicano do país. Para contextualizar sua criação, torna-se necessário resgatar momentos importantes relativos à institucionalização dos cursos de Administração Pública no Brasil. O primeiro deles foi a promulgação Lei ํo. 4769 (1965), que dispõe sobre o exercício da profissão de técnico de administração. De acordo com Coelho e Nicolini (2014), ela foi o referencial para a elaboração, pelo Conselho Federal de Administração, do Parecer 307, de 1966, que estabeleceu o currículo mínimo dos cursos de graduação em Administração e vigorou por 27 anos, detalhando disciplinas e cargas horárias que foram parâmetros para as instituições de ensino em processos de autorização e reconhecimento de cursos.

Coelho (2006) e Vendramini (2013) destacam o currículo mínimo como um instrumento que trouxe consequências negativas 
para os cursos de Administração Pública devido à sua inspiração em preceitos estadunidenses de imbricação entre o público e o privado, nos quais o setor privado provê técnicas de administração de empresas para supostamente tornar a Administração Pública mais eficiente. Nesse sentido, Keinert (2000) observa que, entre as décadas de 1930 e 1970, governar era entendido como administrar empresas estatais em prol do desenvolvimento.

Em 04 de outubro de 1993, a Resolução n. 2 (1993) do Conselho Federal de Educação - CFE, além de oferecer a possibilidade de criação de habilitações específicas nos cursos, alterou a concepção do currículo mínimo para currículo pleno. A solução encontrada para a rigidez do primeiro, se não foi a ideal, representou um avanço. Nesse sentido, Coelho, Olenscki e Celso (2011) esclarecem que, apesar da inflexibilidade da carga horária das disciplinas de natureza obrigatória, havia espaço destinado às disciplinas eletivas - cerca de um terço das grades curriculares que poderiam ser utilizadas para estudos específicos, pertinentes à atuação no setor público. Ainda segundo o autor, observa-se o equívoco de interpretação da Resolução n. 2 (1993), pelas autoridades educacionais, que passaram a entender a Administração Pública como uma das habilitações possíveis do curso de Administração. Assim, a nomenclatura de tais bacharelados seria "graduação em administração, com habilitação em Administração Pública", a ser registrada no verso dos certificados.

A aprovação da Lei n. 9.394 (1996), que estabelece as diretrizes e bases da educação nacional (LDB), trouxe a possibilidade de uma maior flexibilidade curricular. Contudo, apenas em 2005 os cursos de graduação em Administração passam a ser regidos pela Resolução n. 4 (2005), do Conselho Nacional de Educação, que revogou a Resolução n. 2 (1993), admitindo e corrigindo o erro de interpretação, extinguindo as habilitações e definindo a existência das denominações "bacharelado em administração" e "bacharelado em administração Pública", exclusivamente.

Parte dos limites relativos à formação acadêmica com os quais se deparam os cursos de graduação em Administração Pública, dizem respeito à falta de identidade da área. Vendramini (2013) afirma que, de 1966 a 2005, os cursos de graduação em Administração Pública foram considerados apenas uma derivação da administração de empresas.

A ampliação da oferta de cursos de Administração Pública que, segundo o Ministério da Educação (2011b), oscilou de 02, em 2000, para 129, em 2011 - sinaliza a importância adquirida por eles no contexto educacional. Apesar disso, o segmento permaneceu, até 2014, subordinado à legislação dos cursos de Administração. Todavia, o debate sobre as especificidades da formação do gestor público ampliou-se, demonstrando consistência e regularidade. Em parte, esse fato se deve às ações de um movimento denominado Campo de Públicas:

"Campo de Públicas" é uma expressão que vem sendo utilizada, há pouco mais de uma década, no Brasil, por coordenadores, professores, alunos e egressos de cursos de graduação em Administração Pública, Gestão Pública, Políticas Públicas, Gestão de Políticas Públicas e Gestão Social. Refere-se ao campo multidisciplinar de formação acadêmica, científica e profissional de nível superior, assim como da pesquisa científica, comprometido com o aperfeiçoamento democrático e republicano. Tem como objetivo formar profissionais, gerar conhecimentos, desenvolver e difundir metodologias e técnicas, propor inovações sociais e promover processos que contribuam para o aperfeiçoamento da esfera pública, qualificação e melhoria da ação governamental e intensificação e ampliação das formas de participação democrática da sociedade civil na condução dos assuntos públicos. Compreende tanto as ações de governo quanto as de outros agentes públicos não governamentais - sobretudo as organizações da sociedade civil (Pires et al. 2012).

Para operacionalizar e potencializar a comunicação entre os integrantes do movimento, que possui membros nas diversas regiões brasileiras, foram criados dois instrumentos: um grupo de compartilhamento de mensagens e um blog (derivação do termo web log), que reúne documentos que registram as ações do grupo, expressas na forma de cartas e relatórios produzidos coletivamente, a partir de encontros presenciais e discussões virtuais.

Dentre esses documentos, encontra-se a Carta de Balneário Camboriú, de 06 de agosto de 2010, que é considerada uma forte expressão do movimento na articulação pelo reconhecimento das especificidades dos cursos que formam gestores públicos. Ela foi elaborada durante o IX ENEAP - Encontro Nacional de Estudantes de Administração Pública. Nela, docentes e estudantes de Administração Pública, Gestão Pública, Políticas Públicas, Gestão Social e Gestão de Políticas Públicas declararam apoio à aprovação de diretrizes curriculares alinhadas às particularidades de seus cursos.

Em 10 de dezembro de 2006 foi aprovado por unanimidade o Parecer n. 266 (2010) do Conselho Nacional de Educação, que trata das Diretrizes Curriculares Nacionais para os bacharelados em Administração Pública. Anos depois, foi aprovada a Resolução n. 1 (2014), que institui diretrizes específicas para os cursos de graduação em Administração Pública e, apesar da relevância desta última, outros temas continuam na agenda do movimento, com destaque para: a) o diálogo junto ao Conselho Federal de Administração, para que egressos de bacharelados que integram - campo (exceto Administração Pública) obtenham registro profissional e b) o processo de reconhecimento dos cursos, que requer docentes avaliadores sensíveis às diferenças entre bacharelados em Administração e Administração Pública.

Tendo em perspectiva a trajetória dos cursos de formação de gestores públicos, da institucionalização da profissão até o empenho contemporâneo pelo reconhecimento de suas especificidades, é possível observar a crescente complexidade do debate sobre o perfil do profissional apto a servir ao Estado, assim como a contínua afirmação de uma identidade para o segmento, distinta da identidade da gestão e do gestor empresarial. A próxima seção destina-se ao referencial teórico sobre o processo de constituição de identidades individuais, identidades coletivas e a identidade pressuposta de administrador.

\section{Identidades individuais e coletivas}

Considerando a amplitude e complexidade do termo identidade e as muitas possibilidades de sua aplicação, nesse estudo optou-se por adotar os referencias da Psicologia Social por considerar seus princípios de busca de compreensão dos 
fenômenos sociais convergentes com os propósitos desta pesquisa. Segundo Bock (2008), a noção de identidade, para a Psicologia Social, está diretamente relacionada à ideia de processo contínuo constituído a partir das relações que se estabelecem entre o indivíduo e os contextos com os quais ele interage. Jovchelovitch (2004), em seus estudos sobre constituição das identidades, destaca a importância da mesma com a ciência do "entre", ou seja, do estudo das relações de mediação entre o indivíduo e a sociedade.

Para tratar da constituição do movimento Campo de Públicas dentre os inúmeros autores que estudam os movimentos sociais e apresentam contribuições significativas para a discussão de como essas identidades coletivas podem se constituir, Castells (2010) destacou-se ao falar sobre o poder da identidade.

Partindo da concepção de que toda e qualquer identidade é construída socialmente e ocorre em contextos marcados por relações de poder, o autor propõe uma distinção de formas e origens da construção identitária, destacando a identidade legitimadora, a identidade de resistência e a identidade de projeto. A primeira teria sido introduzida pelas instituições dominantes e daria origem à sociedade civil; a segunda possibilitaria a resistência coletiva em casos de opressão através das comunas e a terceira consistiria no processo de construção de sujeito que, mesmo constituído a partir do indivíduo, torna-se ator social e coletivo. Como cada identidade é construída a partir de processos diferenciados, cada processo resulta em um tipo de sociedade. As formas e origens da construção da identidade apresentadas por Castells (2010) foram adotadas como categorias de análise no estudo da constituição do Campo de Públicas. O Quadro 1 apresenta as três formas e origens das identidades e sintetiza uma definição baseada no autor.

\section{Quadro 1 - Formas de identidade coletiva}

\begin{tabular}{c|l}
\hline Forma & \multicolumn{1}{c}{ Definição } \\
\hline $\begin{array}{c}\text { Identidade } \\
\text { legitimadora }\end{array}$ & $\begin{array}{l}\text { É produzida e reproduzida por instituições } \\
\text { hegemônicas, com o intuito de racionalizar e ampliar } \\
\text { a influência de um segmento ou ideologia dominante } \\
\text { sobre os atores sociais. }\end{array}$ \\
\hline $\begin{array}{c}\text { Identidade } \\
\text { de } \\
\text { resistência }\end{array}$ & $\begin{array}{l}\text { Gerada por atores que se encontram em condições } \\
\text { ou posições desvalorizadas ou estigmatizadas pela } \\
\text { lógica hegemônica, construindo, dessa forma, meios } \\
\text { de contraposição baseados em premissas distintas } \\
\text { das que permeiam as instituições sociais. }\end{array}$ \\
\hline $\begin{array}{l}\hat{E} \text { produto da ação de atores sociais que, } \\
\text { empregando materiais culturais que estão ao seu } \\
\text { alcance, elaboram uma nova identidade com } \\
\text { de projeto } \\
\text { capacidade de redefinição de sua posição na } \\
\text { sociedade e, no limite, da própria estrutura social. }\end{array}$ \\
\hline Fonte:
\end{tabular}

Fonte: Baseado em Castells (2010)

Cumpre mencionar que, ainda de acordo com Castells (2010), identidades que surgem a partir de um processo de resistência podem acabar resultando em projetos identitários. Podem, ainda, alcançar status dominante, passando à condição de identidades legitimadoras.

Relacionada à constituição do movimento Campo de Públicas emerge a questão do posicionamento de seus integrantes frente às questões relevantes ao movimento, como o perfil necessário ao gestor público. Para embasar essas discussões, as contribuições de Ciampa $(1987,1994)$ foram essenciais. Seu conceito de identidade como consequência das relações que se estabelecem e também das condições nas quais elas ocorrem, ou seja, dos seus contextos, fortalecem a compreensão do dinamismo e da construção constante também presentes em Castells (2010).

No âmbito desse estudo destaca-se o conceito de identidade pressuposta de Ciampa (1987, 1994), que representou uma importante referência para a discussão do posicionamento dos integrantes do Campo de Públicas. Segundo o autor, ao longo da vida cada indivíduo é apresentado a diferentes conjuntos de papéis. Tais papéis condicionam modos de ser, pensar e agir, nos quais se fazem presentes as expectativas sociais sobre condutas individuais. Essa conceituação relaciona-se ao que se espera do individuo. De acordo com o autor, a partir das identidades que vão sendo apresentadas desde o nascimento, cada indivíduo assume posicionamentos de assimilação (identificação), reposição (acomodação e reforço) ou negação (não identificação).

Cabe lembrar que esse processo torna-se mais ou menos dinâmico em virtude do posicionamento adotado pelo indivíduo. Assim sendo, ao assimilar e repor a identidade a ele apresentada como algo pronto e acabado é como se o processo de metamorfose constante característico do processo de constituição da identidade se estagnasse, passando a identidade a ser mantida, reforçada. É próprio da negação o posicionamento de busca por outras identificações. O Quadro 2 apresentado a seguir foi elaborada com base em Ciampa (1994) e tem por objetivo descrever os comportamentos que acompanham os posicionamentos de assimilação, reposição ou negação tratados pelo autor.

Quadro 2 - Posicionamento do indivíduo diante da identidade pressuposta

\begin{tabular}{c|l}
\hline Posicionamento & \multicolumn{1}{|c}{$\begin{array}{c}\text { Comportamentos que expressam o } \\
\text { posicionamento }\end{array}$} \\
\hline \multirow{3}{*}{ Assimilação } & $\begin{array}{l}\text { Comportamento de assimilação da } \\
\text { identidade pressuposta. Quando o indivíduo } \\
\text { absorve ou internaliza o papel social a ele } \\
\text { atribuído. O indivíduo passa a assumir esse } \\
\text { personagem como parte de sua própria } \\
\text { identidade. }\end{array}$ \\
\hline Reposição & $\begin{array}{l}\text { Comportamento de conformidade } \\
\text { naturalizada. A identidade pressuposta é } \\
\text { percebida como algo dado e natural, } \\
\text { passando a ser reforçada e reposta por meio } \\
\text { dos rituais sociais que fazem com que o } \\
\text { indivíduo mantenha a identidade assimilada. }\end{array}$ \\
\hline Negação & $\begin{array}{l}\text { Comportamento de desconforto e rejeição } \\
\text { em relação à identidade pressuposta. O } \\
\text { indivíduo não se identifica com os papéis a } \\
\text { serem desempenhados e não os assimila, } \\
\text { negando a identidade pressuposta. }\end{array}$ \\
\hline
\end{tabular}

Fonte: Baseado em Ciampa (1994)

A partir do posicionamento individual diante da identidade pressuposta é que a mesma se constitui - e que novas identidades individuais e coletivas são estabelecidas. Contudo, é oportuno lembrar que "[...] as identidades, no seu conjunto, refletem a estrutura social ao mesmo tempo em que reagem sobre ela, conservando-a ou a transformando" (Ciampa, 1994, p. 67). 


\section{A identidade pressuposta do administrador}

Esta seção destina-se à uma revisão sobre os referencias da ciência administrativa e às habilidades e competências necessárias ao administrador presentes em artigos e na legislação educacional, que normatizam os cursos de graduação em Administração e condicionam a identidade pressuposta de administrador. A partir desses referenciais, pretende-se discutir os elementos fundamentais que estabelecem a dita identidade deste profissional, ou seja, a ideia difundida de como deve ser e agir um administrador.

A administração, embora pertença ao conjunto de ações humanas há muitos séculos, passou a apresentar inédita relevância a partir da Revolução Industrial em função das demandas dos processos produtivos que se diversificaram e se tornaram mais complexos. Todavia, a análise metódica da gestão apresentou como marco a publicação "Princípios de Administração Científica", de 1911, escrita por Frederick Winslow Taylor. Embora a evolução da teoria organizacional tenha evidenciado a natureza reducionista do taylorismo, sua vigência histórica e sua relevância contemporânea são inegáveis.

Ainda que adequações tenham sido feitas, os princípios da administração científica continuam presentes nas práticas administrativas. Para Denhardt (2012), a ciência defendida por Taylor representa uma técnica e um mecanismo de produção na qual os gestores passam a ser necessários para projetar, conduzir experimentos, descobrir técnicas eficientes, treinar e supervisionar os trabalhadores.

De acordo com Ramos (1989), a busca pelo sucesso individual, desprendido da ética, é típica da razão instrumental, que é a base da sociedade de mercado e não considera diversos aspectos da vida humana, como a realização pessoal. $O$ autor propõe uma abordagem ampla da teoria das organizações, que incluiria a razão substantiva, por meio da qual o indivíduo poderia conduzir sua vida para a autorrealização. Em relação à razão instrumental, intimamente ligada às organizações, o autor afirma: "[...] ao contrário das organizações substantivas, as organizações formais são fundadas em cálculos e, como tal, constituem sistemas projetados, criados deliberadamente para maximização de recursos" (Ramos, 1989, p. 125).

Prosseguindo na análise da seara administrativa, Tenório (2012) adverte que o trabalhador é um ente manipulado pelo capitalismo. É, em suma, um recurso. Se, no pensamento organizacional advindo de Taylor (1980) bastava ao funcionário ser treinado, hoje, exige-se do "colaborador" capacidade analítica para "otimização" do emprego de meios - não para a reflexão sobre a natureza dos fins a que serve.

Nesse sentido, a condição de administrador traz em si uma grande contradição. Formado para pensar como elite dirigente, sem na maioria dos casos sê-la, eles integram uma classe (a de trabalhadores, pois vendem sua força de trabalho), mas não se percebem exatamente como tal. Nas palavras de Tenório (2014, p. 14), "[...] não sendo donos do capital, são travestidos pelos sistemas de ensino como se o fossem.".
Relacionando a influência de propósitos instrumentais, ditados pelas urgências de mercado com expectativas e objetivos individuais, Ituassu e Tonelli (2012) questionam a noção de "sucesso" como algo a ser perseguido a qualquer custo, além da absoluta responsabilização individual por resultados, que levam o homem organizacional a buscar um estilo competitivo e individualista, considerando as estruturas sociais como se elas fossem naturais e imutáveis. Segundo Wood e Paula (2006), a indústria Pop-Management, literatura voltada para as questões e dilemas próprios dos profissionais da administração, encontra espaço para crescer e influenciar a população em geral e, de modo particular, os estudantes de Administração. Essa mídia popular de negócios valoriza e dissemina ideias, na maioria importadas dos Estados Unidos, com práticas gerenciais de baixo nível de reflexão e crítica, identificando problemas e indicando as soluções, dramatizando e teatralizando a realidade empresarial. Ainda a respeito do fenômeno da literatura popular em gestão, Toledo (2006), que estudou a influência das políticas e práticas de gestão voltadas para a competição, a autonomia, a criatividade e a responsabilização pelos próprios resultados, concluiu que, na busca pelo reconhecimento, os indivíduos passam a agir em função do mercado e da própria organização, perdendo a autonomia sobre a sua identidade pois para se ter sucesso, é preciso adotar atitudes determinadas pela organização e não por referenciais próprios.

O crescimento da literatura popular em gestão tem sido expressivo e seus efeitos podem ser percebidos inclusive na confusão que ela vem causando na percepção de alunos de curso de Administração que, segundo Carvalho, Carvalho e Bezerra (2010), apresentam dificuldades em distinguir um livro de autoajuda, um esotérico e um de literatura pop-management. Em termos de formação acadêmica, a constatação da pesquisa é preocupante a ponto de os autores alertarem que a formação de futuros administradores pode estar gravemente ameaçada. Já em termos legais, a referência que normatiza os cursos de graduação em Administração é a Resolução n. 4 (2005), que estabelece as suas DCNs, e define os parâmetros que as instituições de ensino superior devem seguir para que seus cursos possam ser bem avaliados e reconhecidos. Apesar de deixar a critério de cada instituição como será a estrutura do curso e como ele será oferecido, a resolução estabelece o perfil do egresso, as habilidades e competências esperadas desse profissional e os conteúdos que deverão ser abordados durante a graduação.

Em relação ao perfil desejado do formando em Administração, espera-se que esse profissional seja capaz de compreender questões científicas, técnicas, sociais e econômicas. Segundo Saraiva (2011), em seu estudo sobre a educação superior em Administração no Brasil, a maioria dos cursos não vai além da formação técnica e científica que se estrutura ainda mais no tecnicismo que no cientificismo, uma vez que o número de administradores aptos para a pesquisa é restrito, em grande parte aqueles egressos originários das universidades federais. Ainda segundo o autor, a dimensão humana da formação do administrador se perde em um curso voltado para a técnica e para 
a instrumentalização. Por outro lado, no que toca às questões sociais e econômicas, o autor acrescenta que 0 empreendedorismo remete ao individualismo e à responsabilização do próprio indivíduo pela sua carreira, despolitizando as relações de trabalho.

Como reflexão sobre a formação de administradores, Fischer, Waiandt e Silva (2006 apud Saraiva, 2011, p. 47) afirma: "O conservadorismo na formação de administradores perpassa o contexto, e estabelece um padrão profissional mais comprometido com a preservação de valores e com uma visão de manutenção do passado do que com a inovação, a flexibilidade e rapidez do futuro". Em termos das habilidades e competências estabelecidas pelas DCNs, a análise de Saraiva (2011) deixa claro o distanciamento entre a formação ampla pretendida e o caráter tecnicista que predominou no texto legal, que deixa pequena margem à formação crítica e humanística. Neste sentido, Tenório (2012) faz um alerta para uma crise silenciosa em termos de educação que, segundo o autor, passa por uma "desumanização" que ocorre pela ausência de conteúdos voltados à formação humana que foram substituídos por conteúdos que vão instrumentalizar os alunos e prepará-los para o mercado. Nesse contexto, qual o espaço que resta à formação tecnopolítica? Como formar um administrador público a partir de tais parâmetros normativos e de tal apelo mercadológico? Ao que tudo indica, tal empreendimento, ou seja, formar um administrador público a partir da Resolução nํ 4, de 13 de julho de 2005, comporta uma séria contradição, a de estabelecer a formação de gestores públicos tecnopolíticos segundo diretrizes meramente instrumentais.

Retomando o objetivo inicial da análise dos referenciais da ciência administrativa, que é identificar a identidade pressuposta de administrador, a partir das contribuições de Taylor (1980), Ramos (1989), Tenório (2012), Ituassu e Tonelli (2012), Wood e Paula (2006), Saraiva (2011) e da análise da Resolução n. 4 (2005), é possível perceber que as diretrizes hegemônicas da administração apontam na direção de um profissional altamente produtivo, competitivo, individualista, alinhado ao mercado e ao capital, que se atualiza constantemente e busca o sucesso. Percebe-se uma lacuna em relação à formação humanística, acadêmica, crítica, política e social predominando, então, a técnica e a busca pelos resultados e a pela eficiência. Assim, para fins de análise do posicionamento dos integrantes graduados em Administração que foram entrevistados, considerou-se como Identidade Pressuposta de Administrador aquela com as características acima identificadas.

\section{Procedimentos metodológicos}

O estudo que embasou a elaboração deste artigo é de natureza qualitativa e exploratória. Pesquisas qualitativas, segundo Bogdan e Bikklen (1994), apresentam o ambiente social como fonte dos dados, destacando o pesquisador como instrumento central para análise dos mesmos. Nesses estudos, o processo de investigação é tão relevante quanto o resultado constatado, as evidências coletadas são essencialmente descritivas, o ponto de vista dos sujeitos é especialmente importante e as informações tendem a ser analisadas de forma indutiva.

Inicialmente, partindo de uma revisão de literatura sobre os cursos de Administração Pública no Brasil e sobre a formação do administrador público, além de acompanhar as ações do movimento Campo de Públicas, o estudo buscou referencias fundamentais da ciência administrativa e da Psicologia Social para embasar a análise das entrevistas.

Em resumo, a parte empírica da pesquisa foi constituída a partir da coleta de dados realizada através das entrevistas e da análise dos dados que empregou as técnicas da Análise de Conteúdo segundo Bardin (2011). A seguir, essas duas etapas são detalhadas.

\section{Coleta de dados}

As entrevistas realizadas com integrantes do movimento Campo de Públicas não obedeceram a procedimentos estatísticos. O critério que determinou o conjunto de indivíduos a ser consultado pode ser definido como não probabilístico por julgamento, cabendo aos pesquisadores a seleção dos integrantes com maior capacidade de prover informações.

Assim, para integrar o grupo a ser entrevistado, o integrante do movimento necessitaria ter participado de eventos presenciais, além de manifestações no fórumii de discussões do Campo de Públicas. Dentre os integrantes que satisfaziam a esses dois critérios foi realizada uma consulta para identificar quais deles possuíam graduação em Administração. A partir da consulta, o levantamento apontou catorze possíveis entrevistados, aos quais as Cartas de Apresentação/Convite foram enviadas.

O roteiro da entrevista foi elaborado com base nos objetivos da pesquisa e utilizado na forma de pré-teste para fins de aperfeiçoamento do instrumento e, após a revisão e alguns ajustes, as demais entrevistas foram realizadas. Por meio dos retornos recebidos foram feitas oito entrevistas, todas analisadas por meio da Análise de Conteúdo, metodologia que será explicada mais adiante. A entrevista inicia-se buscando conhecer o perfil do curso de cada entrevistado a partir da natureza predominante dos conteúdos ministrados, as habilidades e as competências priorizadas, a origem da literatura utilizada, o campo e o objeto de reflexão predominante. Na sequência apresentam-se os conceitos de identidade pressuposta e dos processos de assimilação, reposição e negação baseados em Ciampa (1994). Com base na apresentação de tais conceitos, os entrevistados são questionados a respeito do seu posicionamento diante da identidade pressuposta de administrador.

Dando continuidade, a entrevista foi direcionada para a constituição do movimento Campo de Públicas e o entrevistado é indagado sobre o que motivou o seu ingresso no movimento, os fatores que contribuíram para a constituição do mesmo, o objeto de estudo e os referenciais teóricos e normativos do Campo de Públicas. Na parte final da entrevista são apresentadas as três formas de constituição de identidades coletivas segundo Castlles 
(2010): legitimadora, de resistência e de projeto. Em seguida, os participantes são questionados sobre a natureza fundamental da identidade do movimento Campo de Públicas.

\section{Análise de dados}

Como mencionado, as entrevistas foram analisadas por meio da Análise de Conteúdo. Segundo Bardin (2011), a Análise de Conteúdo é um conjunto de técnicas de análise das comunicações que utiliza procedimentos sistemáticos e objetivos de descrição dos conteúdos das comunicações. As três diferentes fases ou etapas da Análise de Conteúdo previstas por Bardin (2011) foram seguidas, sendo elas a pré-análise, a exploração do material e o tratamento dos resultados, todos detalhados a seguir.

\section{1) Pré-análise}

Segundo Bardin (2011, p. 125), "[...] esta etapa possui três missões: a escolha dos documentos a serem submetidos à análise, a formulação das hipóteses e dos objetivos e a elaboração de indicadores que fundamentem a interpretação final."

As ações realizadas nesta etapa foram:

a) Elaboração de algumas categorias de análise a partir do referencial teórico;

b) A elaboração da Carta de Apresentação/Convite e do Roteiro de Entrevista;

c) O levantamento dos integrantes presentes nos eventos e a consulta aos currículos na Plataforma Lattes para identificar aqueles com graduação em Administração;

d) Consulta às participações no fórum;

e) Identificação de catorze integrantes que atendiam aos critérios de participação nos eventos presenciais, participação no fórum e serem graduados em Administração para envio da Carta de Apresentação/Convite;

f) Realização do pré-teste;

g) Revisão do roteiro de entrevistas.

2) Exploração do material

O objetivo desta etapa é proceder à descrição do corpusiii da pesquisa, ou seja, dos textos das entrevistas com base em categorias de análise. De acordo com Bardin (2011, p. 147), "A categorização é uma classificação de elementos constitutivos de um conjunto por diferenciação e, em seguida, por reagrupamento [...]". A autora ainda afirma que a escolha das unidades de registro precisa estar coerente com os objetivos da pesquisa.

As ações realizadas nesta etapa foram:

a) Realização de oito entrevistas;

b) Elaboração de novas categorias de análise, a partir do corpus, além daquelas elaboradas a partir do referencial teórico;

c) Identificação das Unidades de Registro (UR);

d) Criação dos códigos para localização das UR nas entrevistas;

e) Distribuição das UR nas categorias de análise.
3) Tratamento dos resultados, inferência e interpretação.

Nessa fase, os resultados da segunda etapa são explorados de maneira a tornarem-se significativos e válidos. "O analista, tendo à sua disposição resultados significativos e fiéis, pode então propor inferências e adiantar interpretações a propósito dos objetivos previstos - ou que digam respeito a outras descobertas inesperadas." (Bardin, 2011, p. 131). A partir da identificação das Unidades de Registro (UR), realizada na fase de exploração do material, as UR foram distribuídas nas categorias de análise organizadas em quadros elaborados a partir de cada uma das questões. A análise dos dados forneceu as informações necessárias para a apresentação dos resultados da seção seguinte.

\section{A origem do Campo de Públicas na perspectiva de seus integrantes graduados em Administração}

Para a caracterização dos cursos de Administração dos quais os respondentes são egressos, cinco itens foram considerados: conteúdos, habilidades e competências estimuladas, o campo de reflexão, o objeto de reflexão e a literatura utilizada. Os resultados demonstram que tais cursos caracterizaram-se pela ênfase na formação técnica enquanto as habilidades relacionais, além de pouco citadas, aparecem direcionadas, sobretudo, ao setor privado. Fragmentos de alguns discursos expressam o que foi mencionado: a) o curso que fiz (...) teve um enfoque predominantemente instrumental, buscando o desenvolvimento de habilidades mais técnicas (Entrevistado 03), b) considero o curso extremamente normativo (entrevistado 01) e c) com foco nas habilidades relacionais direcionadas sobretudo ao setor privado (Entrevistado 05).

Quanto ao campo de reflexão predominante, o setor privado prevalece e, muitas vezes, além de privado, é industrial. Os cursos apresentaram como objeto de reflexão a grande empresa privada, sendo que nenhum dos entrevistados apontou as discussões sobre as organizações públicas como foco do curso. O público não estatal, reconhecido como terceiro setor, também não foi mencionado. A literatura internacional traduzida e os manuais de administração, inspirados em contextos internacionais - de modo especial no estadunidense - distancia, para os respondentes, a formação de gestores da realidade local e das necessidades da Administração Pública. Referências a esses aspectos foram, assim, apontadas pelos entrevistados: o campo de reflexão era totalmente privado e, muitas vezes, industrial. Tínhamos disciplinas de Administração da Produção, Administração de Materiais, Administração Estratégica e tantas outras voltadas para empresas, em geral, grandes indústrias (Entrevistado 03) e, trabalhávamos muito com literatura internacional traduzida $e$ outros manuais clássicos da administração (Entrevistado 04).

No sentido de apresentar de forma sucinta as informações fornecidas pelos entrevistados a respeito dos cursos de graduação nos quais se formaram, foi organizado um quadro com as características predominantes desses cursos. 
Quadro 3 - Caracterização dos cursos de graduação em administração

\begin{tabular}{l|l}
\hline \multicolumn{1}{c|}{ Tópico } & \multicolumn{1}{c}{ Síntese } \\
\hline Conteúdos & Predominantemente instrumentais; \\
\hline Habilidades & $\begin{array}{l}\text { Mais técnicas que críticas e voltadas para a } \\
\text { administração de empresas. }\end{array}$ \\
\hline Campo de reflexão & O setor privado. \\
\hline Objeto de reflexão & A grande empresa, muitas vezes industrial. \\
\hline Literatura & $\begin{array}{l}\text { Internacional traduzida com destaque para } \\
\text { os manuais de inspiração norte-americana. }\end{array}$ \\
\hline
\end{tabular}

Fonte: Dados da pesquisa, 2014.

A caracterização dos cursos de graduação informada pelos entrevistados reforça os traços característicos da identidade pressuposta de administrador identificada nesse estudo e apresentada anteriormente. É importante lembrar que a legislação que normatiza os cursos de graduação em Administração, a Resolução n. 4 (2005), prevê a formação do administrador voltada para a introdução de modificações nos processos produtivos, para o reconhecimento, definição e solução de problemas, para o desenvolvimento de raciocínio lógico, crítico e analítico, para a demonstração de iniciativa, criatividade, determinação, vontade política e administrativa, vontade de aprender, abertura à mudança e consciência das implicações éticas do exercício profissional. Contudo, de acordo com os relatos, boa parte das habilidades que se espera do administrador não foi objeto de aprimoramento. De modo especial, a habilidade política, relacional, tão necessária à atuação do gestor público, pouco aparece nos discursos dos entrevistados, demonstrando que estas habilidades foram pouco trabalhadas. E quando essas habilidades são mencionadas, isso ocorre associada à participação em disciplinas optativas ou iniciativas de pesquisa e extensão universitária, isto é, não integram a pauta obrigatória de formação. Nesse sentido: a) 0 enfoque era extremamente empresarial, havendo apenas a presença de uma disciplina optativa de Administração Pública, que tive a oportunidade de cursar (Entrevistado 03) e b) meu curso de graduação teve ênfase essencialmente instrumentalizante, com pouco conteúdo de natureza crítica e muita limitação na formação sociopolítica (Entrevistado 04).

No decorrer das entrevistas, os participantes foram convidados à reflexão sobre a identidade pressuposta do administrador e todos os respondentes concordaram que seus cursos de graduação reafirmaram continuamente a identidade pressuposta do profissional de administração. Somente um dos entrevistados não confirmou completamente este fato, ressaltando que, apesar do administrador ser um profissional competitivo, ele não é individualista pois é frequentemente estimulado a trabalhar em equipe.

Todavia, mesmo considerando o estímulo e a preparação para o trabalho em equipe, a lógica da competição continua presente, fato que submete o indivíduo a uma nova e significativa forma de pressão: a pressão dos pares. Em paralelo, equipes decidem sobre a alocação de meios e perseguem metas que são meramente comunicadas. Mesmo a integração ativa ao coletivo reproduz instâncias de dominação, não de emancipação.
Quando questionados a respeito do caminho percorrido desde a graduação até o ingresso no Campo de Públicas, destaca-se a sensação coletiva de desconforto no que se refere à identidade pressuposta do administrador. A maioria dos entrevistados relatou que, com o passar do tempo, seu posicionamento oscilou entre assimilar e, posteriormente, negar tal identidade. Dois discursos foram especialmente claros nesse sentido:

Os processos de ensino e os componentes curriculares do curso de Administração reforçaram os elementos característicos da identidade pressuposta do administrador de empresas. Porém, mesmo durante o processo formativo, devido às atividades no movimento estudantil e no movimento de empresas juniores, comecei a desenvolver um processo gradativo de negação da identidade pressuposta e estereotipada do administrador. Isso fo se refletindo na negação de estágios em empresas privadas e pela busca de estágio e TCC [trabalho de conclusão de curso] em uma organização da sociedade civil. Após isso, toda a minha experiência profissional e meus estudos foram relacionados às organizações da sociedade civil e às organizações governamentais (Entrevistado 03).

Quanto ao processo de assimilação, ele ocorreu no início do curso. Jovem, o estudante aceita muita coisa. Depois, o processo de reposição firmou-se até a metade do curso e a negação passou a ficar mais forte na reta final do curso (Entrevistado 07).

O panorama anteriormente reconhecido alinha-se à observação realizada por Ciampa (1994): a formação identitária não é algo passível de conclusão, que tende a se tornar, portanto, estática. Ao contrário, ela expressa um movimento, uma constante metamorfose.

Outro questionamento dirigido aos administradores, integrantes ativos do Campo de Públicas, diz respeito aos fatores que contribuíram para a organização do movimento. Em uma perspectiva conjuntural, a expansão da oferta e da diversificação de cursos, somada à maior democratização da educação superior, alavancou o debate, o reconhecimento e a articulação de atores. Em uma perspectiva individual, foram destacadas a pró-atividade de alguns acadêmicos da área pública, bem como a clareza, para parte deles, da relevância da ação coletiva, agregadora.

Ainda sobre as razões que culminaram na organização do Campo de Públicas, os respondentes foram convidados à reflexão sobre aspectos que se posicionam entre ação e estrutura, entre o individual e o conjuntural, entre o microssocial e o macrossocial. As respostas evocaram a necessidade de se respeitar as especificidades da área pública e a urgência de se estabelecer uma identidade própria, de se reinventar e de se "reacreditar" na gestão pública. A obrigatoriedade dos cursos do Campo de Públicas de se submeterem às Diretrizes Curriculares Nacionais dos bacharelados em Administração foi citada como descontentamento (ou inimigo) comum e, em consequência, como elemento aglutinador dos esforços coletivos. Os trechos que seguem expressam a percepção de dois dos entrevistados em relação à constituição do movimento:

A constituição do campo teve como fator primordial a defesa das DCNs. Ter um "inimigo comum" foi fundamental naquele momento. Éramos - e ainda somos - tão diversos que este ponto, em especial, nos uniu fortemente e fez o campo se constituir inicialmente. Ao longo do tempo, outros laços e ideais foram sendo costurados, gerando mais integração (Entrevistado 02).

A necessidade de "reinventar" e reacreditar na gestão pública (Entrevistado 03). A busca por uma identidade própria, cujo foco seja diferente da caracterização apenas técnica. (Entrevistado 05) 
No que tange às contribuições do movimento para a Administração Pública, os atores ouvidos foram prudentes em suas afirmações evitando posicionamentos muito enfáticos. De modo tímido, ou pouco articulado, referenciais teóricos não hegemônicos da administração, referenciais multidisciplinares já existentes e não concebidos de forma inédita, têm sido buscados. A mesma prudência nas respostas é perceptível no que se refere aos parâmetros normativos potencializados pelo Campo de Públicas. Emprega-se o termo "potencializados" pois o campo não possui autonomia para instituir referenciais normativos. A articulação em prol de diretrizes curriculares específicas foi mencionada, assim como o debate sobre a pertinência da formação política conjugada à capacitação técnica. Por fim, sobre a natureza da identidade do Campo de Públicas, a maior parte dos entrevistados relatou que há uma característica de resistência, mas também de projeto. A noção de identidade em construção é hegemônica:

O Campo de Públicas exprime uma identidade em formação e esta se aproxima das categorias de "resistência" e de "projeto". Ao longo da trajetória do Campo, a resistência, em especial no episódio das DCNs, se mostrou muito forte. Atualmente, percebo uma migração da resistência para o projeto (Entrevistado 02).

A análise dos discursos permite inferir que a origem da identidade do movimento, em uma perspectiva microssocial e específica - por estar circunscrita às percepções de administradores - caracteriza-se pela resistência ao predomínio de uma identidade pressuposta parcial, que não é compartilhada integralmente por esses profissionais. A lacuna vivenciada motiva a filiação em um movimento com potencial de construção de uma identidade nova, coerente com trajetórias (ou com redefinições de trajetórias) e visões de mundo. Daí a percepção de um projeto que se desdobra à medida que antigas pautas são superadas (como a mobilização por DCNs específicas) e novas ações são propostas (como o diálogo com o Conselho Federal de Administração para concessão de registro aos egressos de determinados bacharelados e a sugestão de meios adequados para 0 reconhecimento dos cursos que integram o Campo de Públicas).

\section{Considerações finais}

Tendo sido adotado como tema central o movimento Campo de Públicas, a pesquisa se encerra apresentando algumas contribuições para a reflexão sobre a constituição do mesmo. Reconhecendo que o tema escolhido para a pesquisa é bastante amplo e complexo, permitindo inúmeras possibilidades de análise, para que os objetivos pudessem ser alcançados, optou-se por analisar a constituição do movimento Campo de Públicas a partir dos referenciais da Psicologia Social e da percepção de integrantes graduados em Administração.

A partir da contextualização da pesquisa e dos referenciais da ciência administrativa, foi possível identificar a identidade pressuposta do administrador evidenciada tanto nas obras de referência quanto na legislação que regulamenta a formação de administradores. A parte empírica da pesquisa, que utilizou as entrevistas como estratégia para a coleta de dados, empregou como metodologia de análise de dados a análise de conteúdo segundo Bardin (2011).

Para que fosse possível conhecer e discutir o posicionamento dos integrantes em relação à identidade pressuposta de administrador, adotou-se como critério para seleção dos entrevistados, além da graduação em Administração, a presença em eventos presenciais do movimento Campo de Públicas e a participação nos fóruns de discussão organizados pelo mesmo. Constatou-se, a partir das falas dos participantes expressas nas entrevistas, que a negação da identidade pressuposta de administrador foi um fator determinante para o seu ingresso no referido movimento.

Por tratar-se de um movimento relativamente recente, que vem se articulando a partir de 2000 e, de modo mais efetivo, a partir de 2010, quando é redigida a Carta de Balneário Camboriú, o movimento Campo de Públicas ainda não possui objeto de estudo claramente definido, referencias teóricos e referenciais normativos que inspirem um amplo consenso entre seus integrantes. Com base na análise das falas dos entrevistados, foi possível constatar que se trata de questões ainda em discussão pelo grupo e que sua explicitação dependerá das articulações ainda em curso. Contudo, a pesquisa evidencia tratar-se de referenciais diferentes daqueles adotados pela ciência administrativa hegemônica.

Quanto à natureza da identidade coletiva em construção, com base na fala dos entrevistados constatou-se que a origem do movimento foi fomentada por um desconforto em relação à imposição de referenciais próprios da administração de empresas expresso através de um posicionamento de resistência diante dessa identidade imposta. Conquistado o primeiro grande objetivo do movimento, que foi a aprovação de DCNs para os cursos do Campo de Públicas, o grupo continua se articulando e construindo novas agendas relacionadas ao reconhecimento da Administração Pública enquanto um campo próprio de formação e de atuação profissional. Tal articulação, evidenciada na fala dos entrevistados, sinaliza em direção à constituição de uma identidade de projeto ancorada na multiplicidade da formação de seus atores e na possibilidade de construção de referenciais multidisciplinares que possam orientar a formação de gestores públicos ou até mesmo a constituição de uma identidade própria para a Administração Pública brasileira.

A riqueza do Campo de Pública está na multiplicidade da formação de seus integrantes e de sua estrutura não hierarquizada, o que favorece a integração e o crescimento do grupo, além do diálogo com outras instâncias e com a sociedade. É necessário que as estruturas mantenham-se democráticas e seus integrantes atentos aos contextos políticos e econômicos que constroem o cenário nacional e internacional. Seu futuro vai depender, em boa medida, de sua capacidade de conciliar ideias e propósitos, bem como a superação de dicotomias. Não é o caso, apenas, de se resgatar a dimensão política da formação dos administradores públicos. É preciso ir além e buscar também a formação técnica adequada às demandas da Administração Pública, não mais se sujeitando ao mimetismo da administração 
de empresas e à imposição de ferramentas e valores que são próprios da administração empresarial.

Outro elemento importantíssimo e que poderá tornar-se mais um ponto fortalecedor do Campo de Públicas são os seus egressos. Sua formação de caráter mais interdisciplinar e conectada com a realidade brasileira poderá permitir o aprofundamento das discussões e contribuir para a construção de novos referenciais para o movimento, próprios da Administração Pública, mas, ainda assim, não isolados dos inúmeros campos de conhecimento que ele congrega. O caráter multidisciplinar do Campo de Públicas, apesar da riqueza que representa, traz consigo um grande desafio: constituir-se em sua particularidade, sem isolar-se e, ainda assim, permitindo a participação de múltiplas áreas do conhecimento.

Finalizando, é oportuno destacar que a base empírica da pesquisa foi desenvolvida a partir de informações fornecidas por integrantes do Campo de Públicas, bacharéis em Administração. Portanto, não é possível estabelecer conclusões que generalizem as percepções dos integrantes. Assim, o presente trabalho pretende contribuir para que se ampliem as discussões em torno da formação de profissionais qualificados para a atuação em Administração Pública Brasileira e que novas pesquisas possam ampliar a análise do movimento Campo de Públicas, que se encontra em processo de constituição de uma identidade de projeto.

\section{Referências}

Bardin, L. (2011). Análise de conteúdo. Lisboa: Edições 70.

Bogdan, R. C., \& Bikklem, S. K. (1994). Investigação qualitativa em educação: uma introdução à teoria e aos métodos. Porto: Porto.

Castells, M. (2010). O poder da identidade. São Paulo: Paz e Terra.

CARVALHO, J. L. F.; CARVALHO, F. A \& BEZERRA, C. (2010) O monge, o executivo e o estudante ludibriado: uma análise empírica sobre leitura eficaz entre alunos de administração. Cadernos EBAPE, 8 (3), 535-549.

Ciampa, A. C. (1987). A estória do Severino e a história da Severina: um ensaio de psicologia social. São Paulo: Brasiliense.

(1994). Identidade. In S. T. M., Lane, \& W., Codo. (Orgs.). Psicologia social: o homem em movimento (pp. 58-75). São Paulo: Brasiliense.

Coelho, F. S. (2006). Educação superior, formação de administradores e setor público: um estudo sobre o ensino de administração pública em nível de graduação no Brasil. Tese de doutoramento não-publicada, Escola de Administração de Empresas de São Paulo, Fundação Getúlio Vargas, São Paulo, Brasil.

, Olenscki, A. R. B, \& Celso, R. P. (2011). Da letargia ao realento: notas sobre o ensino de graduação em administração pública no Brasil no entremeio da crise do Estado e da redemocratização no país (1983-94). Revista de Administração Pública, 45(6), 1707- 1732.

\& Nicolini, A. M. (2014). Revisitando as origens do ensino de graduação em administração pública no Brasil (1854-1952). Revista de Administração Pública, 48(2), 367-388.

Denhardt, R. B. (2012). Teorias da administração pública. São Paulo: Cengage Learning.

Fischer, T., Waiandt, C., \& Silva M.R. (2006). Estudos organizacionais e estudos curriculares: trajetórias simétricas e convergências inevitáveis. Anais do Encontro Nacional dos Programas de Pós-Graduação em Administração, Porto Alegre, RS, Brasil.

Ituassu, C. T., \& Tonelli, M. J. (2012). Notas sobre o conceito de sucesso: sentidos e possíveis (re)significações. Revista de Administração Mackenzie, 13(6), 197-224.

Jovchelovitch, S. (2004) Psicologia social, saber, comunidade e cultura. Psicologia \& Sociedade, 16(2), 20-31.

Keinert, T. M. M. (1994). Os paradigmas da administração pública no Brasil (1900-92). Revista de Administração de Empresas, 34(3), 41-48.

(2000). Administração pública no Brasil: crises e mudanças de paradigmas. São Paulo: Annablume.
Laville, C., \& Dionne, J. (1999). A construção do saber: manual de metodologia da pesquisa em Ciências Humanas. Porto Alegre: Artes Médicas; Belo Horizonte: UFMG

Lei n. 9.394, de 20 de dezembro de 1996. (1996). Estabelece as diretrizes e bases da educação nacional. Diário Oficial da União. Brasília, DF: Casa Civil.

Ministério da Educação. (c2011a). Censo da Educação Superior Recuperado de http://portal.inep.gov.br/web/censo-da-educacaosuperior/evolucao-1980-a-2007.

(c2011b) Microdados para download. Recuperado de http://portal.inep.gov.br/basica-levantamentos-acessar.

Nogueira, M. A. (1998). As possibilidades da política: ideias para a reforma democrática do Estado. São Paulo: Paz e Terra.

Paula, A. P. P. (2005). Administração Pública brasileira entre o gerencialismo e a gestão social. Revista de Administração de Empresas, 45(1), 1-14.

Ministério da Educação. Conselho Nacional de Educação. Recurso contra o Parecer CNE/CES no 266/2010, que instituiu as Diretrizes

Curriculares Nacionais para o curso de graduação em Administração Pública, bacharelado. Diário Oficial [da] República Federativa do Brasil, Brasília, DF, 19 dez. 2013, seção 1, p. 117.

Parecer n. 266, de 10 de dezembro de 2010. (2010). Institui as Diretrizes Curriculares Nacionais do curso de graduação em Administração Pública, bacharelado, e dá outras providências. Brasília, DF: Conselho Nacional de Educação.

Pires, V., Vainer, C., \& Fonseca, S. A. (2012). Uma definição do "Campo de Públicas". Recuperado de https://campodepublicas.wordpress.com/about/

Ramos, A. G. (1989). A nova ciência das organizações. Rio de Janeiro: Ed. da Fundação Getúlio Vargas.

Resolução n. 2, de 4 de outubro de 1993. (1993). Fixa os mínimos de conteúdos e duração do curso de Graduação em Administração. Brasília, DF. Recuperado de http://www.cfa.org.br/download/Resn2_93.pdf

Resolução n. 4, de 13 de julho de 2005. (2005). Institui as Diretrizes Curriculares Nacionais do Curso de Graduação em Administração, bacharelado, e dá outras providências. Brasília, DF: Conselho Nacional de Educação. Recuperado

http://portal.mec.gov.br/cne/arquivos/pdf/rces004_05.pdf.

Resolução n. 1, de 13 de janeiro de 2014. (2014). Institui as Diretrizes Curriculares Nacionais do curso de graduação em Administração Pública, bacharelado, e dá outras providências. Brasília, DF: Conselho Nacional de Educação. Recuperado de http://portal.mec.gov.br/index.

php?option=com_content $\&$ view=article\&id=20138\& Itemid $=866$.

Saraiva, L. A. S. (2011). A educação superior em administração no Brasil e a questão da emancipação: um túnel no fim da luz? Revista Gestão Planejamento, 12(1), 41-60.

Taylor, F. W. (1980). Princípios de administração científica. São Paulo: Atlas.

Tenório, F. G. (2012). O "tipo burguês" e o pensamento organizacional. Colóquio Internacional de Epistemologia e Sociologia da Ciência da Administração, Florianópolis, SC, Brasil, 2.

Toledo, S. (2006). Carreira e identidade: reflexos das exigências mercadológicas na vida pessoal e profissional dos jovens executivos de empresas multinacionais. Anais do Encontro Nacional dos Programas de Pós-Graduação em Administração, Salvador, BA, Brasil, 30.

Vendramini, P. (2013). Análise do curso de Administração Pública da UDESC - ESAG à luz das competências. Tese de doutoramento nãopublicada, Escola de Administração da Universidade Federal da Bahia, Salvador, Brasil.

Wood, T. Jr., Paula, A. P. P. (2006). A mídia especializada e a cultura do management. Organizações e Sociedade, 13(38), 91-105.

\footnotetext{
i Trata-se de nomenclatura utilizada pelos professores, alunos e egressos dos cursos de graduação - bacharelado ou tecnológico - em administração pública (AP), gestão pública (GP), políticas públicas (PP), gestão de políticas públicas (GPP), e gestão social (GS) no Brasil. Surgiu no ato de uma audiência pública no Conselho Nacional de Educação em abril de 2010para se discutir a elaboração de Diretrizes Curriculares Nacionais (DCNs) para os cursos de graduação em administração pública e conexos no país - na ocasião, os 14 cursos presentes, representados por coordenadores e professores, aprovaram tal expressão, sugerida pelo Prof Valdemir Pires (FCL_UNESP), como uma identidade para integrá-los e mobilizá-los. Coelho (2014, p.24),
}

ii O fórum permanente do Campo de Públicas foi um espaço virtual criado para dinamizar as comunicações entre os seus integrantes.

iii O corpus da pesquisa é o conjunto dos documentos tidos em conta para serem submetidos aos procedimentos analíticos. (Bardin, 2011, p.96) 